\title{
Effects of thermal cycles on the mechanical response of pultruded GFRP profiles used in civil engineering applications
}

\author{
João M. Sousa ${ }^{\mathrm{a}, *}$, João R. Correia ${ }^{\mathrm{a}}$, Susana Cabral-Fonseca ${ }^{\mathrm{b}}$, António C. Diogo ${ }^{\mathrm{c}}$ \\ a ICIST, Instituto Superior Técnico, Universidade de Lisboa, Portugal \\ ${ }^{\mathrm{b}}$ National Laboratory of Civil Engineering (LNEC), Lisboa, Portugal \\ ${ }^{\mathrm{c}}$ ICEMS, Instituto Superior Técnico, Universidade de Lisboa, Portugal
}

\section{A R T I C L E I N F O}

\section{Article history:}

Available online 14 June 2014

\section{Keywords:}

GFRP

Durability

Thermal cycles

Vinylester

Polyester

Experimental tests

\begin{abstract}
A B S T R A C T
This paper presents a literature review and results of an experimental study about the effects of thermal cycles on the physical and mechanical properties of pultruded glass fibre reinforced polymer (GFRP) profiles used in civil engineering structural applications. The GFRP profiles used in this study present similar fibre architecture, differing only in their matrix nature: unsaturated polyester and vinylester. Small-scale coupons obtained from both types of GFRP profiles were exposed to a Mediterranean range of thermal variations $\left(-5^{\circ} \mathrm{C}\right.$ to $40^{\circ} \mathrm{C}$ ) for up to 190 cycles in a dry condition. The effects of such exposure on the physical and mechanical response of the GFRP materials were assessed and compared using the following experimental techniques: (a) dynamic mechanical analyses (DMA) to assess the viscoelastic behaviour; (b) tensile, flexural and interlaminar shear tests, to evaluate the mechanical properties; and (c) scanning electron microscopy (SEM), to monitor the potential changes in the microstructure due to the degradation (if any) caused by the thermal cycles, as well as the possible changes into the main mechanisms of fracture. After exposure to thermal cycles, the viscoelastic behaviour of the GFRP profiles presented only slight changes, indicating no significant degradation, neither in the matrix structure nor at the fibre-matrix interphase. In terms of mechanical properties, both types of GFRP materials suffered slight changes regarding tensile and interlaminar shear properties. Flexural properties were more affected, particularly the flexural modulus, especially in the first cycles, as degradation tended to stabilize for increasing cycles. The GFRP profile made of vinylester resin presented better overall performance than the one made of polyester, especially regarding the tensile properties. SEM observations of the surfaces of fracture of mechanically tested pultruded specimens showed two main mechanisms of crack propagation: cohesive rupture (matrix cracking), where the crack propagates inside the matrix, and adhesive rupture (fibre-matrix debonding), where the crack propagates at the interface fibre-matrix. Degradation of the polyester matrix caused by the thermal cycles is evidenced by extensive matrix microcracking and increased fibre-matrix debonding. The vinylester matrix resists better to such degradation as fibre-matrix debonding occurs in less extent, and matrix microcracking is scarcely present.
\end{abstract}

(c) 2014 Elsevier Ltd. All rights reserved.

\section{Introduction}

Fibre reinforced polymer (FRP) materials present great potential for civil engineering structural applications, due to their several advantages when compared with traditional materials [1-3] that include high specific strength and stiffness, low self-weight, ease of handling, electromagnetic transparency, low maintenance requirements and high durability even in relatively harsh environments.

\footnotetext{
* Corresponding author. Tel.: +351964139222.

E-mail address: joao.sousa@civil.ist.utl.pt (J.M. Sousa).
}

Among FRP materials, glass fibre reinforced polymer (GFRP) pultruded profiles are being used in a growing number of applications, because they offer the above-mentioned advantages at a relatively competitive cost. There are already several examples of bridges and buildings comprising GFRP structural elements, in both new construction and rehabilitation of degraded infrastructure [4-6]. One of the most important fields of application of GFRP profiles is the replacement of reinforced concrete or steel deteriorated bridges decks, located in cold environments, with frequent use of de-icing salts that have a corrosive effect on those traditional materials [7].

The main disadvantages of GFRP profiles are their brittle behaviour and the low elasticity and shear moduli, with their design 
being often governed by deformability or instability phenomena and seldom allowing the full exploitation of the material resistance $[8,9]$. In spite of anecdotal evidence of improved durability, another factor that is delaying the widespread acceptance of GFRP profiles for civil engineering structural applications is the lack of comprehensive and validated data about their durability. In fact, although there is a wealth of information available concerning their shortterm behaviour, their durability has not yet been investigated to an extent that provides enough confidence to construction agents, namely when compared with traditional materials. The need to document, evaluate and quantify the durability performance of GFRP profiles is particularly relevant for civil engineering structural applications, as the majority of the projects are developed considering relatively long service lives, often higher than 50 years $[10,11]$.

Thermal cycles are one of the most relevant types of environmental agents that FRP materials are subjected to, namely in outdoor applications. The concerns regarding thermal cycles are related not only with the exposure to sub-zero temperatures, but also to the thermal variations (amplitude and heating or cooling rates). There is anecdotal evidence that exposure of FRP composites to sub-zero temperatures can cause matrix hardening and microcracking, as well as fibre-matrix debonding [11]. The exposure to thermal variations can also promote fibre-matrix debonding due to the different coefficients of thermal expansion of the fibres and the matrix and the consequent build-up of internal stresses. Although thermal cycles can have a potential deleterious effect in the performance of FRP materials, studies reported in the literature are relatively scarce. As discussed in Section 2, the materials and exposure conditions used in those studies can vary significantly. Furthermore, in general, few properties are assessed.

The study presented in this paper is part of a broader research project which aims at evaluating the durability of GFRP pultruded profiles when exposed to environmental agents representative of different civil engineering applications [12,13]. This paper, in particular, presents results of an experimental study about the degradation of two commercial GFRP profiles made of alternative resin matrix - unsaturated polyester (UP) and vinylester (VE) - both comprising identical fibre content and reinforcement architecture, after being exposed to thermal cycles, simulating outdoor applications in Mediterranean mild climates. The performance of both profiles following such exposure conditions was analysed and compared regarding their physical, viscoelastic and mechanical responses. Complementary data provided by scanning electron microscopy (SEM) analysis was also gathered.

\section{Literature review}

One of the first studies addressing the effects of thermal cycles on the performance of FRP composites was presented by Dutta and Hui [14]. The authors analysed the variation on the flexural properties suffered by two different FRP composites made of isophthalic polyester resin after being exposed to thermal cycles between $-60^{\circ} \mathrm{C}$ and $50^{\circ} \mathrm{C}$. The first FRP composite, reinforced with E-glass rovings and produced by pultrusion, was subjected to 100 cycles, whereas the second one, reinforced with S2-glass fabric and produced by the vacuum bag technique, was subjected to 250 cycles. The E-glass composite specimens suffered severe degradation after exposure to the thermal cycles, exhibiting extensive cracking in the interior of the material that the authors attributed to the formation of residual stresses from curing. Therefore, no further flexural tests were performed on this material. In opposition, the S2-glass composite specimens showed no visible signs of degradation and their Young's and shear moduli suffered very slight reductions of $6.4 \%$ and $6.3 \%$, respectively. Although the performance of the pultruded specimens was unsatisfactory, the authors recognised that the limits of temperatures used in the tests were too extreme and unlikely to be experienced in real applications.

Gomez and Casto [15] evaluated the flexural properties of two commercially available GFRP pultruded systems, made of either isophthalic polyester or vinylester resins, after immersion in a $2 \%$ sodium chloride solution and subsequent exposure to 300 cycles of freezing and thawing between $-17.8^{\circ} \mathrm{C}$ and $4.4^{\circ} \mathrm{C}$ (typical of very cold climates). Results obtained showed considerable reductions of both flexural strength and stiffness, which were more pronounced in the vinylester system: flexural strength decreased $19 \%$ and $32 \%$ respectively in the polyester and vinylester systems, while the corresponding elasticity modulus reductions were $18 \%$ and $35 \%$.

Zhang et al. [16] evaluated the effects of freeze and freeze-thaw exposure on FRP composite systems used in column wrapping. The authors characterised the material response and failure mechanisms through NOL-ring burst tests, short-beam-shear tests, dynamical mechanical thermal analyses and microscopy. Different systems encompassing a range of materials, reinforcement forms and processing techniques were investigated. These included E-glass, carbon and aramid fibre types and polyester and epoxy matrices. Several sample specimens were immersed in a $5 \% \mathrm{NaCl}$ solution for a period of five weeks and later subjected to freeze and freeze-thaw regimes for 90 and 180 cycles $\left(24 \mathrm{~h}\right.$ at $-26{ }^{\circ} \mathrm{C}$ with $24 \mathrm{~h}$ at $23^{\circ} \mathrm{C}$ for six and twelve months). For all composite systems, the authors reported a general decrease in NOL based tensile strength and glass transition temperature levels at 180 cycles (10-16\% and $4-13 \%$ reductions, respectively). Regarding short beam shear strength, significant reductions were obtained (8-25\% reductions) with the exception of one composite system, whose strength increased $2 \%$.

Karbhari et al. [17,18] studied the hygrothermal degradation of ambient cured E-glass and carbon reinforced vinylester composites produced by the wet layup process due to exposure to 100 freeze thaw cycles (between $-10{ }^{\circ} \mathrm{C}$ and $22.5^{\circ} \mathrm{C}$ ), both in the presence of aqueous solutions (deionized water and salt water) and just ambient humidity. Changes in mechanical (tensile and compressive properties) and thermo-mechanical dynamic characteristics were measured, and short-term effects of environmental exposure were assessed. For both types of composites, the authors reported significant reductions in the mechanical properties due to the exposure to thermal cycles (8-9\% and $9-18 \%$ reduction of tensile and transverse compressive strengths, respectively), whose magnitude increased in the presence of aqueous solutions (14-16\% and $30 \%$, respectively) due to moisture diffusion and wicking of $\mathrm{NaCl}$. The values of the glass transition temperature $\left(T_{g}\right)$, determined from both the $\tan \delta$ curve peaks and the $E^{\prime}$ decay curves, were also reduced after freeze-thaw cycles (reductions of $3-7 \%$ and $3-10 \%$, respectively in dry and wet conditions).

Tann and Delpak [19] reported the influence of freeze and thaw actions on the tensile properties of aramid, carbon and glass FRP fabric strips (unfortunately, the authors did not specify the resin matrix) commonly used in structural strengthening. The material was subjected to freeze thaw cycles $\left(21\right.$ cycles between $-20^{\circ} \mathrm{C}$ and $25^{\circ} \mathrm{C}$ ) at every three days for a period of nine weeks. The tensile strength of carbon and aramid FRP specimens presented a slight increase of $1.0-1.5 \%$, whereas that of glass FRP suffered a very slight reduction of $1 \%$. The tensile modulus of all FRP systems varied 1.0-2.5\%. Given the scatter of experimental data, the authors concluded that freeze and thaw actions do not appear to have significant influence on the mechanical properties of common FRP strips used in civil engineering applications.

Haramis et al. [20] examined the performance in tension (stiffness, strength and failure strain) of pultruded glass-vinylester 
and glass-epoxy cross-ply laminates in different moisture and freeze-thaw ageing environments. The freeze-thaw conditioning parameters varied between $-17.8^{\circ} \mathrm{C}$ and $4.4^{\circ} \mathrm{C}$ with a ten cycle per day rate (75\% cycle time for freezing and $25 \%$ for thawing). One set of samples was previously saturated and remained fully immersed during freeze-thaw cycling and a complementary set remained dry before and during the duration of the experiment. Within each set, part of the samples remained unloaded, whereas other samples were loaded in four-point bending (maximum axial strain of $0.55 \%$ ). Results indicated significant degradation of tensile strength $(-40.5 \%)$ and no significant degradation of stiffness $(+9.8 \%)$ for all types of specimens due to saturation. In opposition, freeze-thaw conditioning and loading did not seem to cause any effects on the tensile properties.

Sheikh and Tam [10] published an experimental study on the effects of freeze thaw cycles on the tensile properties of two FRP systems, made of epoxy resin reinforced with either E-glass or carbon fibres. In order to understand the effect of the extreme Canadian winter condition, specimens were exposed to either (i) freeze-thaw cycles immersed in water (between $-20^{\circ} \mathrm{C}$ and $20^{\circ} \mathrm{C}$ ), (ii) sustained loading and (iii) a combination thereof. The exposure to freeze-thaw cycles and sustained loading caused low to moderate changes in the tensile properties of the materials. For the GFRP specimens, the maximum reduction of tensile strength was only $2.5 \%$, whereas the tensile modulus even increased up to $7.5 \%$. For the CFRP specimens, maximum reductions of tensile strength and stiffness were $12 \%$ and $7 \%$, respectively. For both materials, the synergetic effect of sustained loading proved to be reduced or even negligible.

$\mathrm{Wu}$ et al. [21] investigated the effects of freeze-thaw on the flexural properties and glass transition temperature of GFRP skins used in bridge decks. To this end, laminates made of E-glass fibres and vinylester resin were subjected to thermal cycles between $-17.8^{\circ} \mathrm{C}$ and $4.4^{\circ} \mathrm{C}(625$ cycles of $2 \mathrm{~h}$ or 250 cycles of $5 \mathrm{~h}$ ). This investigation considered the combined effects of exposure to distilled water and salt-water immersion, as well as ambient temperature. In addition, several specimens were also subjected to simultaneous environmental exposure and sustained loading up to $25 \%$ of the ultimate strain. After thermal cycling no significant change was found in the flexural strength and storage modulus, as they were within data scatter. The authors presented also small reductions $(1 \%)$ in the storage modulus of prestrained specimens subjected to 250 thermal cycles immersed in water.

Kim et al. [22] studied the degradation of interfacial shear strength of two different pultruded E-glass vinylester composite rods. The specimens were immersed in an alkaline solution (simulating the chemical composition of concrete pores solution) and exposed to 110 thermal cycles varying between $-25^{\circ} \mathrm{C}$ and $30^{\circ} \mathrm{C}$. In this study, the reductions the interfacial shear strength caused by the environmental exposure were very significant in one of the reinforcing bars (29\%) and reduced in the other (6\%).

Li et al. [23] published an investigation about the freeze-thaw resistance (tensile properties) of unidirectional glass, carbon and basalt fibre reinforced laminates fabricated with epoxy systems using the wet-layup process. The materials were subjected to 90 cycles of $24 \mathrm{~h}$, including a freezing state $\left(12 \mathrm{~h}\right.$ at $\left.-30^{\circ} \mathrm{C}\right)$ and a thawing state $\left(12 \mathrm{~h}\right.$ at $\left.30^{\circ} \mathrm{C}\right)$. The tensile strength and modulus obtained for the glass and basalt composite systems after 90 cycles were within the experimental error, thus indicating a negligible effect of the freeze-thaw cycles. However, carbon fibre specimens presented reductions of tensile strength and modulus of respectively $16 \%$ and $18 \%$.

Ludovico et al. [24] examined the tensile properties of CFRP laminates after exposure to freeze-thaw cycling. A series of mechanical tests were carried out on three types of epoxy based matrixes as well as CFRP laminates processed with the same resins.
A set of 80 and 210 cycles were conducted between $-5{ }^{\circ} \mathrm{C}$ at a relative humidity (RH) of $0 \%$ for $6 \mathrm{~h}$ and $40{ }^{\circ} \mathrm{C}$ at $80 \% \mathrm{RH}$ for $15 \mathrm{~h}$ with transition periods of $1.5 \mathrm{~h}$. Such $24 \mathrm{~h}$ cycles were used to simulate a typical Mediterranean day. After 210 thermal cycles all epoxy systems showed slight tensile strength reductions (1.9-8.5\%). The authors reported also an increase in the tensile modulus for two systems (4.7-5\%) and a slight reduction (1.9\%) for the other.

Aniskevich et al. [25] conducted experimental investigations regarding the short-term exposure of polyester-based pultruded GFRP to severe freeze-thaw cycles between $-30^{\circ} \mathrm{C}$ and $20^{\circ} \mathrm{C}$, in both dry and wet condition. Flexural properties and linear thermal expansion coefficient changes were assessed. After 125 cycles, the authors reported an increase of the flexural modulus (14\%) and a slight decrease of the flexural strength (13\%). No remarkable differences were encountered between dry and wet condition specimens. The $T_{g}$ suffered a slight decrease (5\%).

Table 1 presents a summary of the literature review described in this section, indicating the main details concerning each study. Overall, the experimental work reported above, regarding the effects of thermal cycles on the physical and mechanical properties of pultruded GFRP composites, is very limited. Moreover, the test methods used in these studies vary considerably, with respect to the constituent materials (fibre and resin nature), manufacturing processes, type (number of cycles and temperature range) and exposure conditions (dry, saturated in different solutions, loaded/ unloaded) and characterisation techniques. Thus, some results are contradictory and present clearly distinctive degradation magnitudes. Furthermore, the studies reported above do not provide comprehensive understanding of the basic degradation mechanisms involved in the variation of GFRP properties. In addition, thermal cycle ranges used in the studies reported above have limited relation with civil engineering application in mild climates, such as outdoor applications in Mediterranean climates, where the minimum temperatures are seldom lower than $-5^{\circ} \mathrm{C}$ and $\max$ imum temperatures generally do not exceed $40^{\circ} \mathrm{C}$. It is also worth mentioning that none of the studies reported above provide degradation models able (i) to predict/simulate the effects of thermal cycles on the GFRP physical and mechanical properties and/or (ii) to link experimental laboratory results with actual/field exposure during service life.

\section{Materials}

The materials used in the experimental study consist of two square tubular section $(50 \mathrm{~mm} \times 50 \mathrm{~mm}$ and $5 \mathrm{~mm}$ thickness) off-the-shelf pultruded GFRP profiles, manufactured and supplied by ALTO Perfis Pultrudidos. Both profiles comprise alternating layers of E-glass unidirectional rovings and strand mats embedded in either unsaturated polyester resin (UP profile) or vinylester resin (VE profile). Pultruded profiles were produced by pulling the E-glass fibres with a silane sizing through a bath of resin, at an average speed of $0.25 \mathrm{~m} / \mathrm{min}$. The tubular sections were produced in a heated die, where temperatures vary between $130^{\circ} \mathrm{C}$ (entrance) and $165^{\circ} \mathrm{C}$ (exit). The UP resin is used in most structural applications when there are no particular requirements in terms of environmental harshness, whereas the VE resin is often selected for relatively harsh or corrosive environments applications. Both profiles have the same glass fibre content and architecture, as shown in Fig. 1, thus allowing for a direct comparison of the durability performance of their resins.

\section{Methods}

Specimens with appropriate dimensions (for physical-chemical and mechanical characterisation, detailed below), were cut from the $5 \mathrm{~mm}$ thick walls of both tubular profiles in the longitudinal 
Table 1

Summary of previous studies concerning the effects of thermal cycles on the properties of FRP composites.

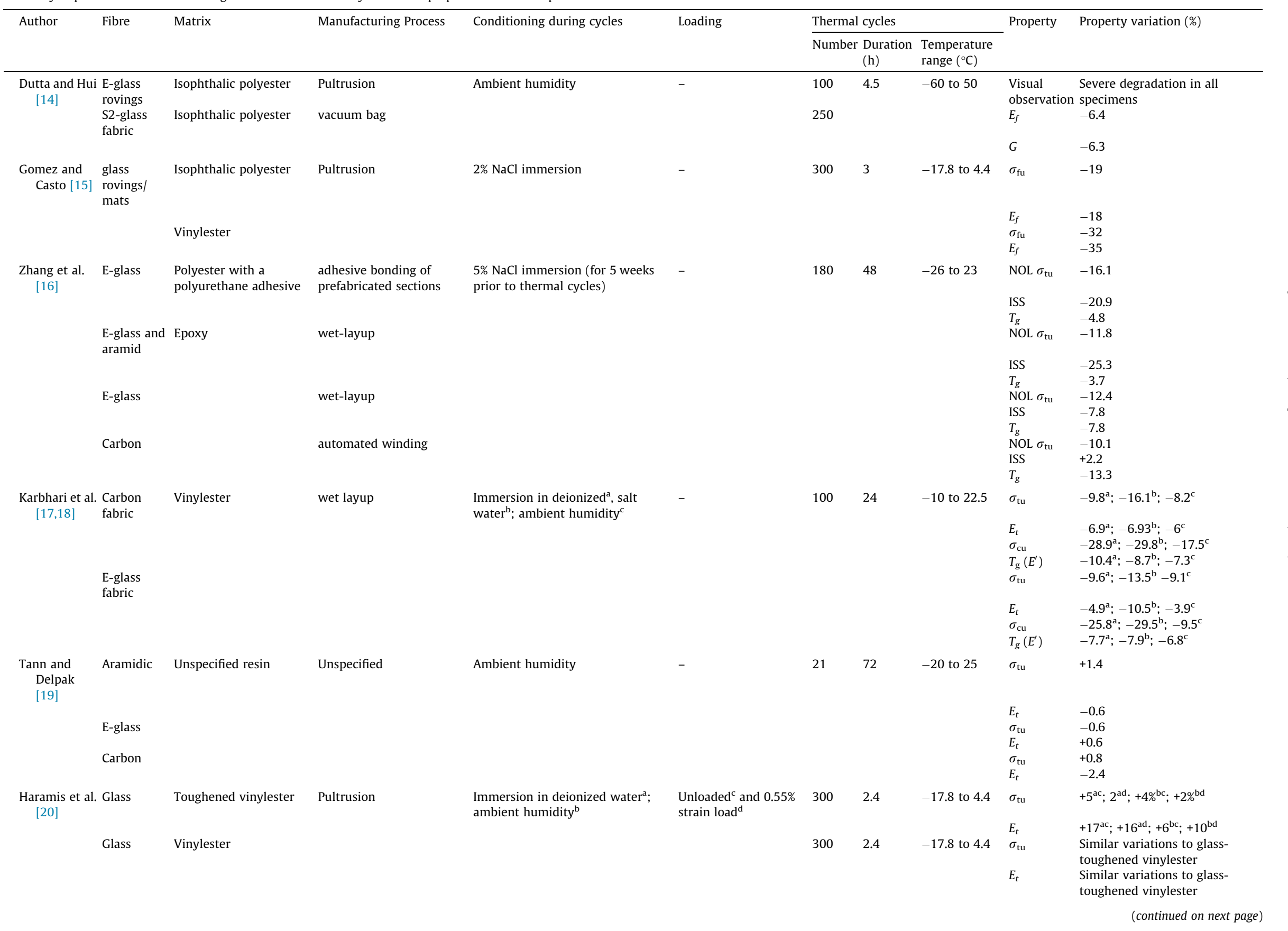




\begin{tabular}{|c|c|c|c|c|c|c|c|c|c|c|}
\hline \multirow[t]{2}{*}{ Author } & \multirow[t]{2}{*}{ Fibre } & \multirow[t]{2}{*}{ Matrix } & \multirow[t]{2}{*}{ Manufacturing Process } & \multirow[t]{2}{*}{ Conditioning during cycles } & \multirow[t]{2}{*}{ Loading } & \multicolumn{3}{|c|}{ Thermal cycles } & \multirow[t]{2}{*}{ Property } & \multirow[t]{2}{*}{ Property variation (\%) } \\
\hline & & & & & & Number & $\begin{array}{l}\text { r Duration } \\
\text { (h) }\end{array}$ & $\begin{array}{l}\text { Temperature } \\
\text { range }\left({ }^{\circ} \mathrm{C}\right)\end{array}$ & & \\
\hline \multirow{4}{*}{$\begin{array}{l}\text { Sheikh and } \\
\text { Tam [10] }\end{array}$} & Glass & Epoxy & & & & 300 & 2.4 & -17.8 to 4.4 & $\begin{array}{l}\sigma_{\mathrm{tu}} \\
E_{t}\end{array}$ & $\begin{array}{l}\text { Similar variations to glass- } \\
\text { toughened vinylester } \\
\text { Similar variations to glass- } \\
\text { toughened vinylester }\end{array}$ \\
\hline & $\begin{array}{l}\text { Glass (SHE- } \\
51 \mathrm{~A})\end{array}$ & Epoxy & Unspecified & Immersion in deionized water ${ }^{\mathrm{a}}$ & $\begin{array}{l}\text { Unloaded }^{\mathrm{c}} \text { and } 30 \% \text { of } \\
\text { ultimate load }\end{array}$ & 300 & 6 & -20 to 20 & $\sigma_{\mathrm{tu}}$ & $-0.6^{\mathrm{ac}} ;-2.5^{\mathrm{ad}}$ \\
\hline & $\begin{array}{l}\text { Carbon } \\
\text { (SCH-41S) }\end{array}$ & & & & & 300 & 6 & -20 to 20 & $\begin{array}{l}E_{t} \\
\sigma_{\mathrm{tu}}\end{array}$ & $\begin{array}{l}+7.5^{\mathrm{ac}} ;+3.4^{\mathrm{ad}} \\
-9.2^{\mathrm{ac}} ;-11.6^{\mathrm{ad}}\end{array}$ \\
\hline & & & & & & & & & $E_{t}$ & $-6.7^{\mathrm{ac}} ;-6.7^{\mathrm{ad}}$ \\
\hline Wu et al. [21] & Glass & Vinylester & Unspecified & $\begin{array}{l}\text { Immersion in deionized }{ }^{\mathrm{a}} \text {, salt } \\
\text { water }^{\mathrm{b}} \text {; ambient humidity }{ }^{\mathrm{c}}\end{array}$ & $25 \%$ of ultimate load & 250 & 5 & -17.8 to 4.4 & $\sigma_{\mathrm{fu}}$ & $-10^{\mathrm{a}} ;-3^{\mathrm{b}} ;-1^{\mathrm{c}}$ \\
\hline Kim et al. [22] & E-glass & $\begin{array}{l}\text { Vinylester } \\
\text { Modified vinylester }\end{array}$ & Pultrusion & Alkaline solution (pH13) & - & 60 & 24 & -25 to 30 & $\begin{array}{l}\text { ISS } \\
\text { ISS }\end{array}$ & $\begin{array}{l}-29.3 \\
-5.9\end{array}$ \\
\hline \multirow[t]{3}{*}{ Li et al. [23] } & & Epoxy & Wet layup & Ambient humidity & - & 90 & 24 & -30 to 30 & $\begin{array}{l}\sigma_{\mathrm{tu}} \\
E_{t}\end{array}$ & $\begin{array}{l}-18 \\
-16\end{array}$ \\
\hline & Glass & & & & & & & & $\begin{array}{l}\sigma_{\text {tu }} \\
E_{t}\end{array}$ & $\begin{array}{l}+5 \\
-4\end{array}$ \\
\hline & Basalt & & & & & & & & $\begin{array}{l}\sigma_{\mathrm{tu}} \\
E_{t}\end{array}$ & $\begin{array}{l}+4 \\
-1\end{array}$ \\
\hline \multirow{3}{*}{$\begin{array}{l}\text { Ludovico } \\
\quad \text { et al. [24] }\end{array}$} & Carbon & Commercial epoxy & Wet layup & Ambient humidity & - & 210 & 24 & -5 to 40 & $\sigma_{\mathrm{tu}}$ & -8.5 \\
\hline & & Neat epoxy & & & & & & & $\begin{array}{l}E_{t} \\
\sigma_{\mathrm{tu}} \\
E_{t}\end{array}$ & $\begin{array}{l}+5.5 \\
-3.3 \\
-1.9\end{array}$ \\
\hline & & Nanocomposite system & & & & & & & $\begin{array}{l}\sigma_{\mathrm{tu}} \\
E_{\mathrm{t}}\end{array}$ & $\begin{array}{l}-1.9 \\
+4.7\end{array}$ \\
\hline \multirow[t]{2}{*}{$\begin{array}{l}\text { Aniskevich } \\
\quad \text { et al. [25] }\end{array}$} & E-glass & Polyester & Pultrusion & $\begin{array}{l}\text { Immersion in deionized water } \\
\text { ambient humidity }\end{array}$ & - & 125 & 24 & -30 to 20 & $\sigma_{\mathrm{fu}}$ & $+2.5^{\mathrm{a}} ;-13.3^{\mathrm{b}}$ \\
\hline & & & & & & & & & $\begin{array}{l}E_{f} \\
T_{g}\end{array}$ & $\begin{array}{l}+5.9^{\mathrm{a}} ;+14.4^{\mathrm{b}} \\
-3.0^{\mathrm{a}} ;-5.2^{\mathrm{b}}\end{array}$ \\
\hline
\end{tabular}

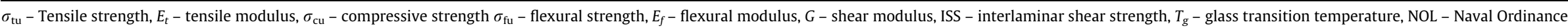
Laboratory.

The footnotes a-d point the type of conditioning and/or loading to its respective property variation. 

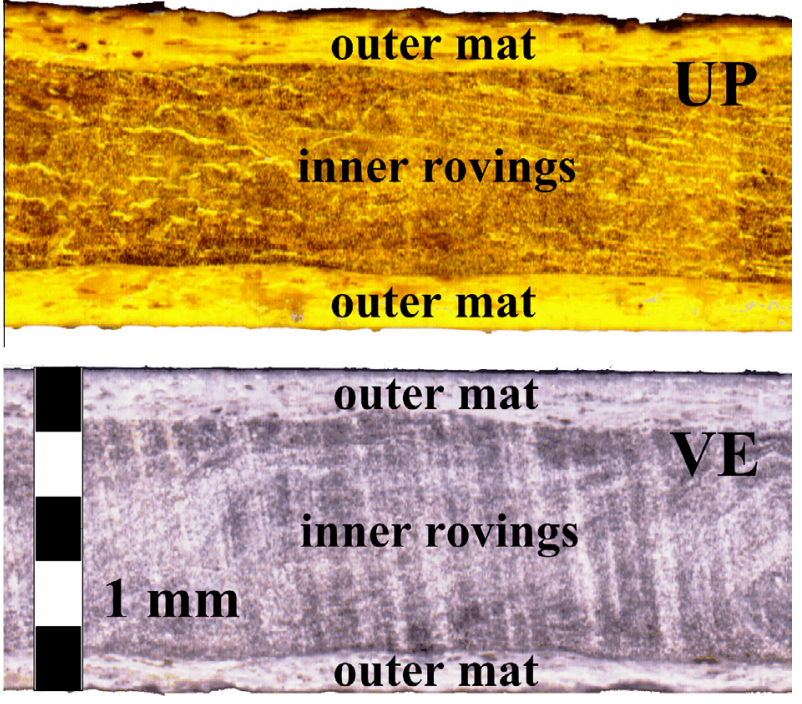

Fig. 1. UP and VE profiles cross-sections, divided by outer mats and inner rovings.

direction, using a water-cooled diamond saw blade. After pre-conditioning until constant weight (in a ventilated chamber at $50{ }^{\circ} \mathrm{C}$ ), specimens were exposed to the referred thermal cycles.

In order to adequately assess (i) the changes in the physical and mechanical properties of the GFRP composites as well as (ii) the mechanisms of degradation as a result of thermal cycles, specimens were subjected to three sets of cycles (70, 120 and 190 cycles) in a conditioning chamber from Aralab, model Fitoclima 300 EDTU. Each thermal cycle had a total duration of $14 \mathrm{~h}$, with $6 \mathrm{~h}$ at $-5^{\circ} \mathrm{C}, 6 \mathrm{~h}$ at $40^{\circ} \mathrm{C}$ and $2 \mathrm{~h}$ of continuous heating or cooling between those two reference temperatures, as illustrated in Fig. 2. Because there is no information on the literature or in test standards specifying the minimum number of thermal cycles GFRP materials must resist for a given service life and climate, the authors considered existing specifications for other construction materials (e.g., ASTM D6944 [26], EN 1504-2 [27], EN 1504-3 [28], EN 1504-4 [29], EN 539-2 [30]). Most of these documents refer to coatings and non-structural materials (generally designed for service lives that do not exceed 25 years), specifying no more than 50 thermal cycles. Therefore, the authors considered that about 200 cycles would be a reasonable figure for GFRP pultruded profiles used in structural applications (generally, with a service life of 50 years), particularly for a Mediterranean (mild) climate.

At predefined times batches test specimens used for physical and mechanical characterisation were (i) removed from the previously mentioned conditioning chamber, (ii) stored in polyethylene hermetically closed recipients, and then (iii) placed inside a room with temperature controlled at $23( \pm 2){ }^{\circ} \mathrm{C}$. Prior to testing,

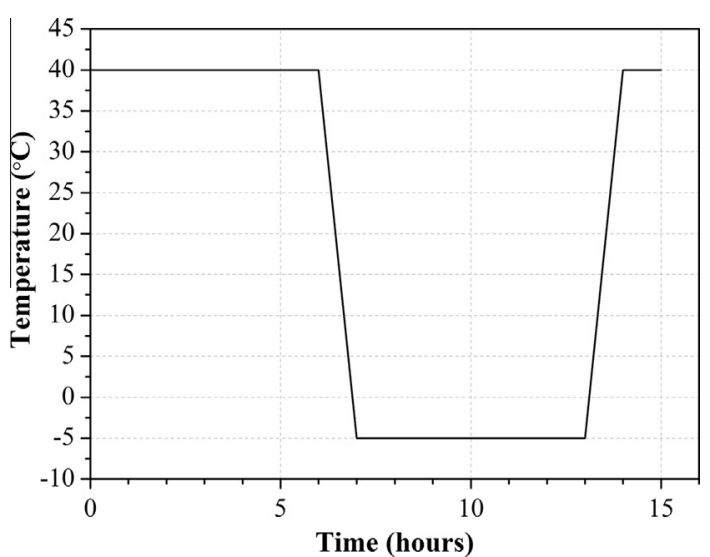

Fig. 2. Thermal cycle profile.

specimens were removed from the polyethylene recipients and immediately tested without any further conditioning.

Infrared spectra of both profiles were assessed for initial characterisation by means of Fourier Transform Infrared (FTIR) spectroscopy in the $450-4000 \mathrm{~cm}^{-1}$ region. For these measurements, powder samples, scraped from the surfaces of test specimens, were mixed with dry spectroscopic grade potassium bromide and pressed into pellets. 32 scans were collected and averaged at a spectral resolution of $4 \mathrm{~cm}^{-1}$ in a Thermo Scientific Nicolet spectroscope. This technique was used to provide initial detailed data on the surface constituents of the GFRP material.

DMA tests were performed to analyse the viscoelastic behaviour of the GFRP materials, as well as to assess the glass transition temperature. DMA tests allow assessing changes/degradation in the resin matrix (e.g., plasticisation and hydrolysis caused by hygrothermal exposure) and at the fibre-matrix interface level that may not be directly characterised by mechanical tests. DMA tests also provide distinct advantages over other forms of characterisation since they are able to assess the effects of subtle physical and chemical changes in the polymer matrix, allowing the evaluation of its contribution to the composite behaviour and durability. DMA tests were carried out in accordance with parts 1 and 5 of ISO 6721 standard [31]. Three-point bending type clamp specimens with $5 \mathrm{~mm} \times 15 \mathrm{~mm} \times 60 \mathrm{~mm}$ were tested at a constant frequency of $1 \mathrm{~Hz}$ and strain amplitude of $15 \mu \mathrm{m}$, using a DMA analyser from TA Instruments, model Q800. The analyses were conducted from room temperature up to $200^{\circ} \mathrm{C}$, at a rate of $2{ }^{\circ} \mathrm{C} /$ min. Three replicates were tested for each set of thermal cycles.

For each set of thermal cycles, five samples were submitted to different mechanical tests in the longitudinal direction: (a) flexural tests, (b) tensile tests, and (c) interlaminar shear tests. Flexural properties were measured by means of three-point bending

Table 2

Physical-chemical properties of GFRP profiles (un-aged).

\begin{tabular}{|c|c|c|c|c|}
\hline Property & Method & & UP profile & VE profile \\
\hline Chemical composition & FTIR & & \multicolumn{2}{|c|}{$\begin{array}{l}\text { FTIR spectra consistent with unsaturated polyester } \\
\text { or vinylester, with presence of calcium carbonate and silica }\end{array}$} \\
\hline Glass fibre content [\%] & Calcination & [\%] & $68.4 \pm 1.8$ & $68.7 \pm 0.4$ \\
\hline Density & Immersion & {$\left[\mathrm{g} / \mathrm{cm}^{3}\right]$} & $1.87 \pm 0.11$ & $2.03 \pm 0.05$ \\
\hline \multirow[t]{2}{*}{$T_{g}$} & DMA & $e_{\text {initial }}^{\prime}\left[{ }^{\circ} \mathrm{C}\right]$ & $107.9 \pm 10.8$ & $98.6 \pm 7.0$ \\
\hline & & $\tan \delta\left[{ }^{\circ} \mathrm{C}\right]$ & $146.0 \pm 2.3$ & $126,9 \pm 2.3$ \\
\hline \multirow[t]{5}{*}{ Mechanical properties } & Tensile response & $\sigma_{t}[\mathrm{MPa}]$ & $406.2 \pm 30.9$ & $393.3 \pm 51.2$ \\
\hline & & $E_{t}[\mathrm{GPa}]$ & $37.6 \pm 2.6$ & $38.9 \pm 4.1$ \\
\hline & Flexural response & $\sigma_{f}[\mathrm{MPa}]$ & $472.2 \pm 76.4$ & $537.2 \pm 73.1$ \\
\hline & & $\left.E_{f}[\mathrm{GPa}]\right)$ & $22.6 \pm 4.4$ & $28.4 \pm 3.4$ \\
\hline & Interlaminar shear & $\sigma_{\text {sbs }}[\mathrm{MPa}]$ & $38.5 \pm 2.7$ & $39.2 \pm 4.2$ \\
\hline
\end{tabular}




\section{UP Profile}

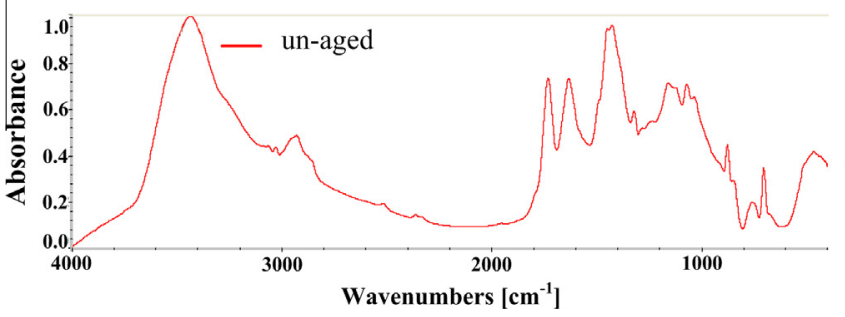

VE Profile

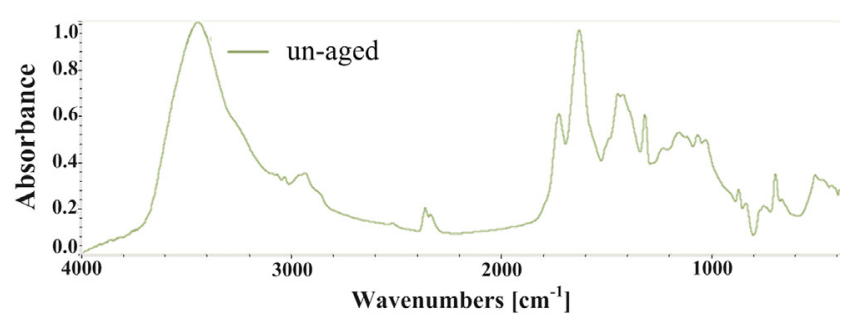

Fig. 3. FTIR spectra of surface un-aged material of a UP (left) and VE (right) profile.

flexural tests performed according to ISO 14125 standard [32] in rectangular test specimens with $5 \mathrm{~mm} \times 15 \mathrm{~mm} \times 150 \mathrm{~mm}$ with a $100 \mathrm{~mm}$ span. Tests were carried out at a loading rate of about $2 \mathrm{~mm} / \mathrm{min}$, using a system from Seidner Form Test, constituted by a hydraulic press with $10 \mathrm{kN}$ load capacity. Tensile properties were conducted according to parts 1 and 4 of ISO 527 standard [33] in rectangular test specimens with $5 \mathrm{~mm} \times 25 \mathrm{~mm} \times 300 \mathrm{~mm}$, without end tabs. Tests were carried out in an Instron universal testing machine with a load capacity of $100 \mathrm{kN}$ at a $2 \mathrm{~mm} / \mathrm{min}$ loading rate. Interlaminar shear tests were carried out in accordance with ASTM D2344 standard [34] in rectangular test specimens with $5 \mathrm{~mm} \times 15 \mathrm{~mm} \times 30 \mathrm{~mm}$ with a $20 \mathrm{~mm}$ span. Tests were carried out at a loading rate of $1 \mathrm{~mm} / \mathrm{min}$, with the above-mentioned Seidner Form Test system.

SEM analysis was performed in the two following electron microscopes: (i) Hitachi S-2400 Scanning Electron Microscope with a tungsten thermionic emission gun and elemental analysis (Bruker). It is equipped with an Energy Dispersive Spectrometer (EDS) and a digital image acquisition and analysis feature. The maximum accelerating voltage is $25 \mathrm{kV}$ and the resolution is $5 \mathrm{~nm}$ at $25 \mathrm{kV}$ (maximum magnification $=3 \times 10^{5} \mathrm{X}$ ); (ii) $\mathrm{JEOL}$ JSM-7001F Scanning Electron Microscope with a Schottky emission gun, elemental and diffraction pattern analysis (Oxford INCA 250). It is equipped with secondary and backscattered electron detectors, EDS with light elements detector, a system for detecting and processing electron backscattered diffraction patterns, and a digital image acquisition and analysis feature. The maximum accelerating voltage is $30 \mathrm{kV}$ and the resolution is $1.2 \mathrm{~nm}$ at $30 \mathrm{kV}$ (maximum magnification $=10^{6} \mathrm{X}$ ). In the SEM experiments, the surface of the specimens has been sputter coated with either a gold layer or a gold/palladium layer, using the standard procedures. All the SEM observations reported here were performed on the crack surfaces of the specimens after mechanical rupture, in three different testing geometries: tensile, bending and interlaminar shear modes. Both aged (190 thermal cycles) and unaged specimens were considered. SEM has been widely used in fibrereinforced composite materials to identify the following failure mechanisms by detailed analysis of fractured specimens [35-40]:

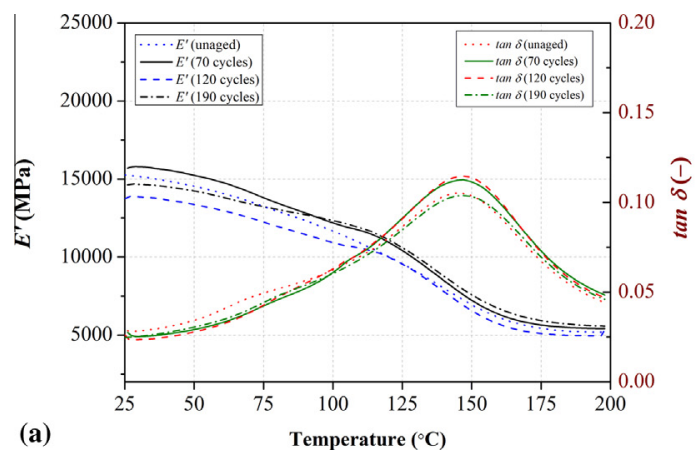

delamination, interlaminar matrix cracking, longitudinal matrix splitting, fibre-matrix debonding, fibre pull-out and fibre fracture.

\section{Results and discussion}

For clarity of the discussion, the results are presented and analysed as related to the method of characterisation used. However, wherever relevant, results of different tests are cross-referenced. The results obtained in this study are also benchmarked with those obtained in studies reported in the literature that are comparable with ours in terms of fibre reinforcement and resin system.

\subsection{Initial characterisation}

The initial characterisation results for both UP and VE profiles before thermal cycles exposure are listed in Table 2 (average \pm standard deviation values are shown, where applicable).

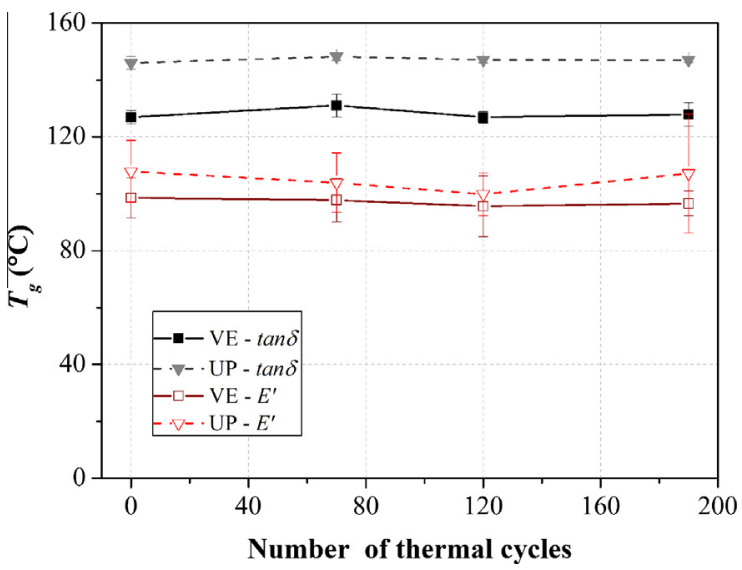

Fig. 5. $T_{g}$ vs. number of thermal cycles.

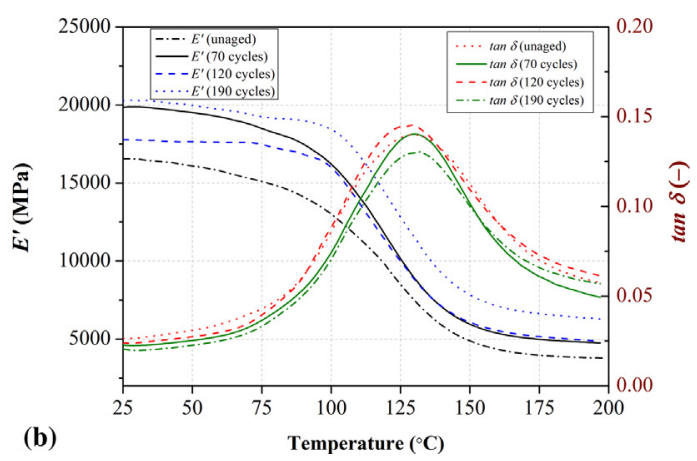

Fig. 4. DMA plots for (a) UP profile and (b) VE profile, before and after different thermal cycles. 
Table 3

Retention (percentage) of physical and mechanical properties after exposure to thermal cycles.

\begin{tabular}{|c|c|c|c|c|c|}
\hline \multirow[t]{2}{*}{ Profile } & \multirow[t]{2}{*}{ Property } & & \multicolumn{3}{|c|}{ Number of cycles } \\
\hline & & & 70 & 120 & 190 \\
\hline \multirow[t]{7}{*}{ UP } & \multirow[t]{7}{*}{$T_{g}[\%]$} & $E^{\prime}$ & $96.3 \pm 10.0$ & $92.6 \pm 7.5$ & $99.4 \pm 19.5$ \\
\hline & & $\tan \delta$ & $101.5 \pm 0.8$ & $100.8 \pm 0.6$ & $100.7 \pm 0.5$ \\
\hline & & $\sigma_{\text {tu }}[\%]$ & $91.6 \pm 11.2$ & $94.0 \pm 16.2$ & $86.9 \pm 25.0$ \\
\hline & & $E_{t}[\%]$ & $88.3 \pm 7.6$ & $97.8 \pm 13.7$ & $85.3 \pm 12.3$ \\
\hline & & $\sigma_{\mathrm{fu}}[\%]$ & $87.3 \pm 16.3$ & $90.3 \pm 19.9$ & $89.8 \pm 17.8$ \\
\hline & & $E_{f}[\%]$ & $85.6 \pm 17.6$ & $81.0 \pm 10.4$ & $76.5 \pm 20.2$ \\
\hline & & $\sigma_{\text {sbs }}[\%]$ & $91.5 \pm 15.6$ & $93.5 \pm 5.8$ & $88.6 \pm 11.4$ \\
\hline \multirow[t]{7}{*}{ VE } & \multirow[t]{7}{*}{$T_{g}[\%]$} & $E^{\prime}$ & $99.2 \pm 7.8$ & $97.0 \pm 11.2$ & $98.0 \pm 4.5$ \\
\hline & & $\tan \delta$ & $103.2 \pm 3.1$ & $100.0 \pm 1.6$ & $100.8 \pm 3.2$ \\
\hline & & $\sigma_{\text {tu }}[\%]$ & $102.7 \pm 6.9$ & $103.6 \pm 5.0$ & $107.8 \pm 3.7$ \\
\hline & & $E_{t}[\%]$ & $95.1 \pm 8.1$ & $100.2 \pm 9.2$ & $92.6 \pm 8.1$ \\
\hline & & $\sigma_{\mathrm{fu}}[\%]$ & $88.5 \pm 17.6$ & $84.2 \pm 12.4$ & $86.9 \pm 13.7$ \\
\hline & & $E_{f}[\%]$ & $77.5 \pm 17.7$ & $73.6 \pm 12.9$ & $75.4 \pm 16.8$ \\
\hline & & $\sigma_{\mathrm{sbs}}[\%]$ & $94.9 \pm 12.1$ & $91.9 \pm 6.7$ & $97.8 \pm 10.1$ \\
\hline
\end{tabular}

Chemical composition, determined by FTIR spectroscopy and presented in Fig. 3, showed little differences between the two materials analysed. In fact, both profiles spectra are quite similar. Peaks' localisations and intensity confirmed the presence of ester, as well as aromatic and aliphatic structures, which are in the molecular structure of both unsaturated polyester and vinylester resins. The comparison of the two spectra shows, however, that the absorption band located at $1730 \mathrm{~cm}^{-1}$ is more intensive in the polyester spectrum, which is consistent with its higher number of ester groups. FTIR spectra also showed the existence of calcium carbonate (filler) and silica (from E-glass fibres).

The glass fibre content was determined by the calcination method described in ASTM D3171 [41] and the density was determined by the immersion method described in ISO 1183 [42]. Those physical properties were slightly higher for the VE profile compared to the UP profile.

The glass transition temperature (obtained from the peak of the loss factor curve, $\tan \delta$, and from the beginning of the storage modulus decay curve $E_{\text {initial }}^{\prime}$ ) is lower in the VE profile. The mechanical performance loss for UP and VE profiles starts above $108{ }^{\circ} \mathrm{C}$ and $99^{\circ} \mathrm{C}$, respectively.

All mechanical tests (flexural, tensile and interlaminar shear properties) indicate linear elastic behaviour until rupture for both profiles, as expected. Regarding the tensile properties (strength, $\sigma_{t}$, and stiffness, $\left.E_{t}\right)$ and interlaminar shear strength $\left(\sigma_{\mathrm{sbs}}\right)$, both profiles present similar behaviour. However, concerning the flexural behaviour, the VE profile presented superior performance in terms of both flexural strength $\left(\sigma_{f}\right)$ and stiffness $\left(E_{f}\right)$.

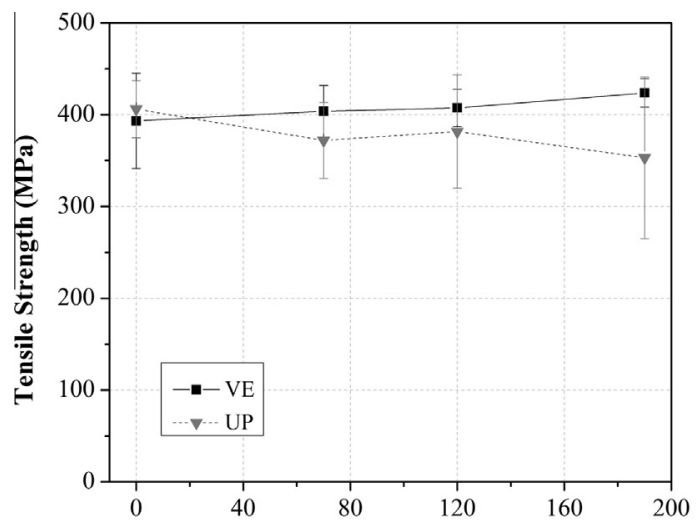

(a)

Number of thermal cycles

\subsection{Effects of thermal cycles}

\subsubsection{DMA based characterisation}

Fig. 4(a) and (b) show representative DMA curves for UP and VE profiles, respectively, before and after exposure to different thermal cycles (for each set of cycles one representative curve among three replicates is presented).

The storage modulus $\left(E^{\prime}\right)$ curves represented in the left axis of the graphs present the characteristic slope in the glass transition region. The loss factor $(\tan \delta)$ curves plotted in the right axis indicate the typical maximum peak in the same region. The pattern of the $E^{\prime}$ curves in the glass transition region reflect essentially modifications in the polymeric matrix, which changes from a glassy to an elastomeric state, due to its viscoelastic nature. In fact, the reinforcing material (glass fibres) does not present stiffness loss for this temperature range. However, as already mentioned, matrix-fibre interphase quality can influence DMA results.

Fig. 4 shows that, in general, following the exposure to the thermal cycles, the progression of the $E^{\prime}$ and $\tan \delta$ curves exhibited by both materials was kept constant, indicating that no significant changes occurred in their viscoelastic properties.

Fig. 5 plots for both profiles the change in $T_{g}$, determined from both $E^{\prime}$ (taken as the extrapolated onset of its sigmoidal change, according to the definition of ASTM E1640 [43]) and $\tan \delta$ curves, as a function of the number of thermal cycles. Table 3 presents for both profiles the retention of $T_{g}$ obtained from both DMA curves when compared to the un-aged materials. It can be seen that both profiles present a very slight increasing pattern in the $T_{g}$ defined from the $\tan \delta$ curve peak and a slight decreasing pattern in the $T_{g}$ defined from the $E^{\prime}$ decay curve, more pronounced in the UP profile, which exhibited a maximum reduction of $7 \%$ after 120 cycles. After 190 cycles, the reduction in the $T_{g}$ of both profiles defined from $E^{\prime}$ was less than $2 \%$, which is almost negligible and well within the experimental uncertainty. These results indicate that changes in $T_{g}$ due to thermal cycles are not relevant, being much less significant when compared to those caused by accelerated hygrothermal ageing [2].

Despite some differences (in terms of materials, manufacturing process, and/or test conditions) between the present study and those performed by Karbhari et al. [18] and Aniskevich et al. [25], the range of variation in DMA results was similar.

\subsubsection{Tensile response}

Fig. 6(a) and (b) plots for both profiles the variation of the tensile strength and modulus, respectively, as a function of the number of thermal cycles.

For the UP profile, in spite of the scatter in the experimental data, it can be seen that there is a general decreasing trend of

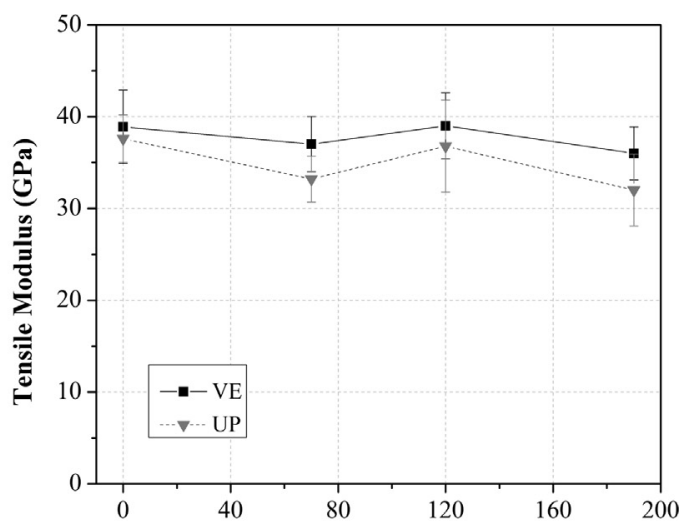

(b) Number of thermal cycles

Fig. 6. Tensile (a) strength and (b) modulus vs. number of thermal cycles. 

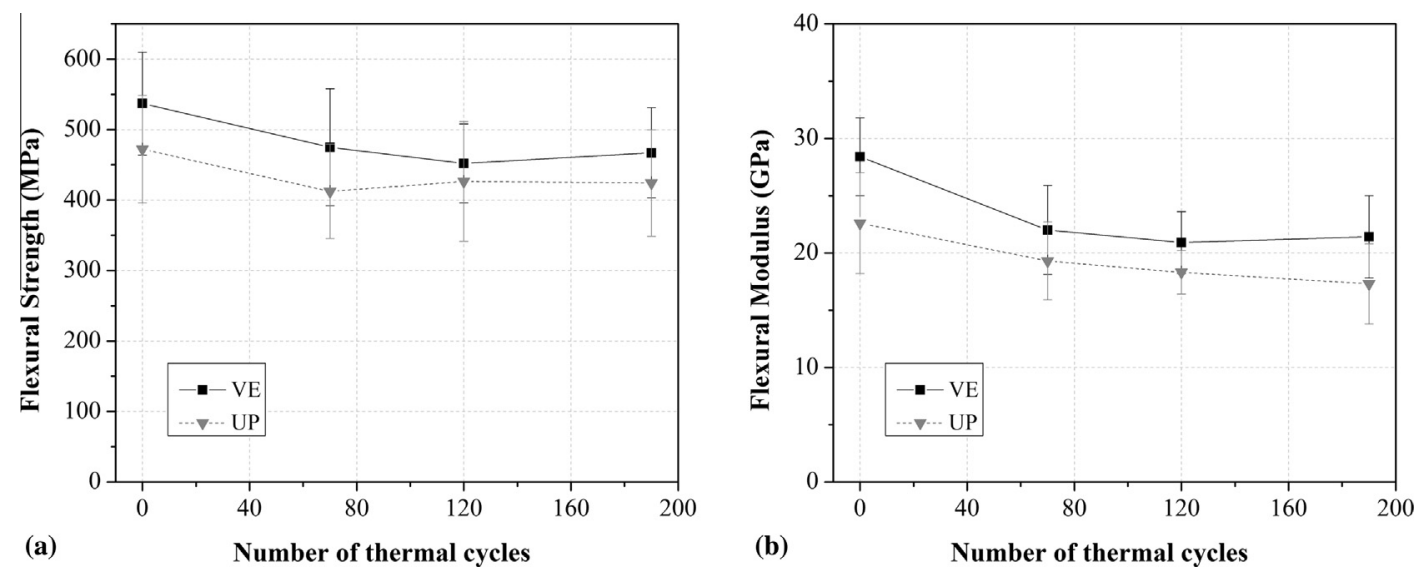

Fig. 7. Flexural (a) strength and (b) modulus vs. number of thermal cycles.

the tensile strength with the increase in the number of thermal cycles. The tensile strength retention of the UP profile was $92 \%$, $94 \%$ and $87 \%$ after respectively 70,120 , and 190 cycles. The VE profile exhibited an opposite variation trend, with tensile strength increasing 3\%, 4\% and $8 \%$ after respectively 70,120 and 190 cycles. In what concerns stiffness, the tensile modulus of both profiles presented a general decreasing tendency. After 190 cycles, the tensile modulus retentions were $85 \%$ and $93 \%$ in the UP and VE profiles, respectively.

As already mentioned, freeze-thaw exposure may cause fibrematrix debonding and matrix microcracking, causing a decrease in both tensile strength and modulus. The UP profile exhibited precisely a decrease in both tensile strength and modulus, which seems to indicate that the above-mentioned mechanisms were effectively caused by the thermal cycles. In what concerns the VE profile, not only the influence of those mechanisms on the tensile properties is not visible, but also there was even a slight strength increase. It is likely that the higher range of temperature exposure $\left(40^{\circ} \mathrm{C}\right)$ increased the degree of matrix reticulation, thereby contributing to the slight increase of tensile strength and to the negligible change in the tensile modulus. DMA results did not show such post-cure phenomena, but DMA curves obtained may have been influenced by the competing phenomena of matrix/interface degradation due to the thermal cycles and post-cure due to increased temperature, which had been reported when the same material was exposed to accelerated hygrothermal ageing [12].

Karbhari et al. [18] reported reductions in the tensile strength of an E-glass vinylester composite. Despite some differences to our study, which may be explained by the differences in the test programme (manufacturing process, temperature ranges and duration), it is worth mentioning that the magnitude of tensile strength variations was similar (although of different signs), whereas the tensile modulus variation was very similar when compared with that of the VE profile. Tann and Delpak [19] observed no significant influence of freeze-thaw cycles, which is most likely related with the very reduced number of cycles used in this study. In the experimental program performed by Haramis et al. [20], similar results were obtained on glass-vinylester composites: the authors reported a slight increase in tensile strength, which was not affected by the application of sustained (flexural) loading, and attributed such increase to material desiccation during conditioning. In the work reported by Sheikh and Tam [10], the tensile properties of a glass-epoxy composite system suffered also very little changes.

The comparison of the results obtained in the present study with the ones reported in the literature that are more comparable shows that, despite some differences in the manufacturing

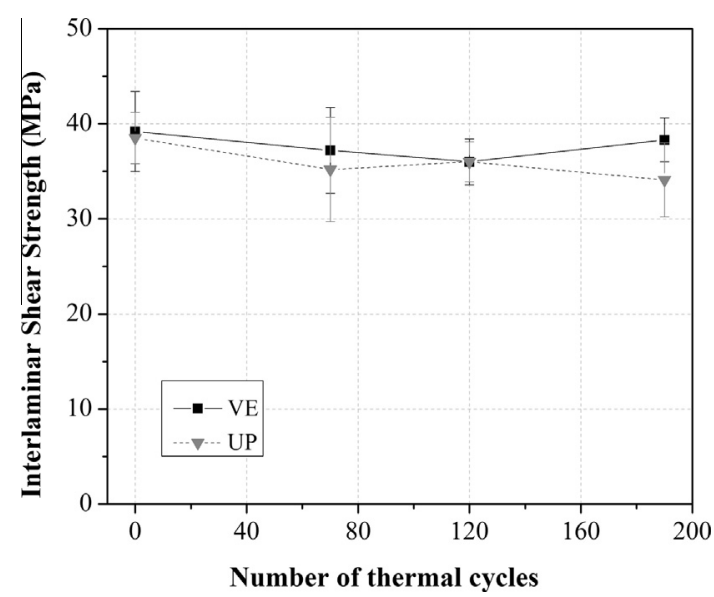

Fig. 8. Interlaminar shear strength vs. number of thermal cycles.

processes, resin matrixes and thermal cycles (number and duration of cycles, minimum and maximum temperatures), there is an overall general agreement between the test data, indicating that the tensile properties of GFRP composites suffer only slight changes due to thermal cycles (lower than 15\%).

\subsubsection{Flexural response}

Fig. 7(a) and (b) illustrate for the UP and VE profiles the variation in flexural strength and modulus, respectively, both as a function of the number of thermal cycles.

Although the scatter of the results obtained is rather significant, it seems clear that the flexural strength and modulus of both profiles are negatively affected by the exposure to the thermal cycles. In addition, the overall trends of variation exhibited by the flexural strength and modulus curves seem to indicate that those parameters are stabilizing for increasing thermal cycles, i.e. the degradation is more important during the first cycles.

In terms of flexural strength, the UP profile exhibited retentions of $87 \%$ (minimum value), $90 \%$ and $89 \%$ after respectively 70, 120 and 190 thermal cycles. The VE profile experienced slightly higher strength degradation, with the previous figures being respectively $88 \%, 84 \%$ and $87 \%$. In terms of flexural modulus, the performance reduction caused by the thermal cycles was higher than that of flexural strength. Flexural modulus retentions after 70,120 and 190 cycles were respectively $86 \%$, $81 \%$ and $76 \%$ for the UP profile and $78 \%, 74 \%$ and $75 \%$ for the VE profile. 


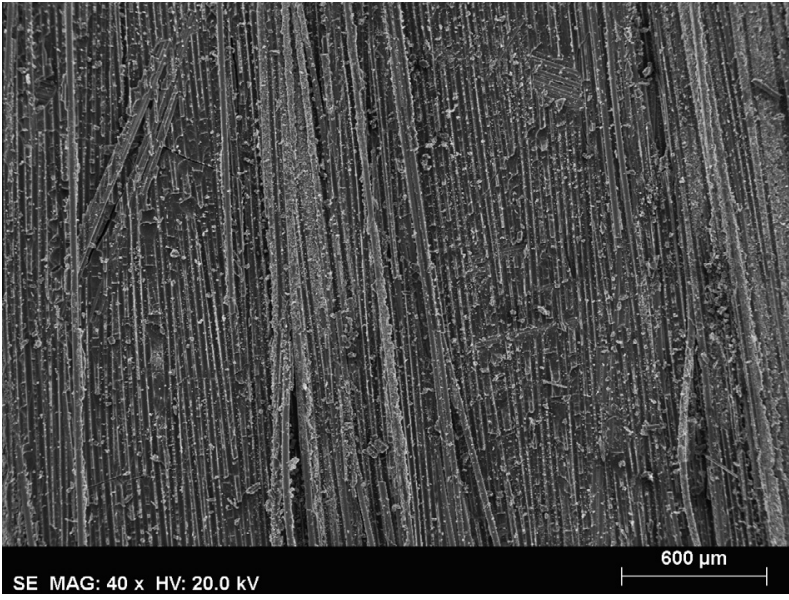

Fig. 9. SEM micrograph of unaged UP pultruded specimen after bending test (cracked surface).

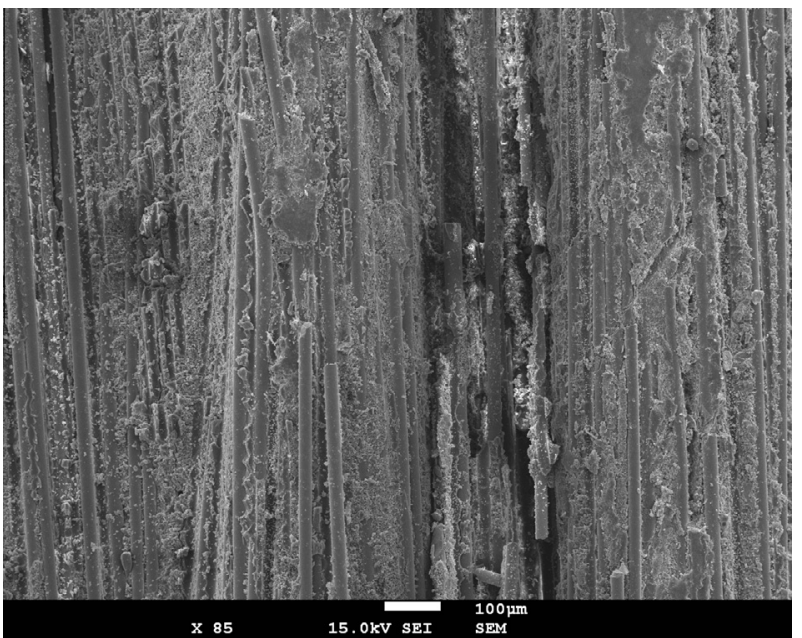

Fig. 10. SEM micrograph of unaged VE pultruded specimen after bending test (cracked surface).

In the study performed by Dutta and Hui [14], the pultruded Eglass fibre polyester system (more similar to the material tested in our study) presented extensive visible degradation and cracks after 100 cycles. In opposition, the S2-glass reinforced polyester composite system did not show signs of significant flexural modulus variation. Gomez and Casto [15] also reported considerable reductions of flexural strength and stiffness of both isophthalic polyester or vinylester resins, particularly for the latter resin, which is in accordance with our results. The flexural strength results reported by Aniskevich et al. [25] are in general agreement with our test data, in opposition to the flexural modulus which contrasts with our results; differences may be due to post-curing phenomena and matrix hardening caused by the exposure to low temperatures.

In general, the results obtained in the present study together with "more comparable" data reported in the literature show that exposure to thermal cycles likely to be observed in civil engineering applications negatively affects the flexural properties of glassreinforced polymer composites (more intensely than the tensile properties), particularly the flexural modulus. Such increased magnitude should be caused by the stronger dependency of flexural properties on the resin matrix and the fibre-matrix interphase

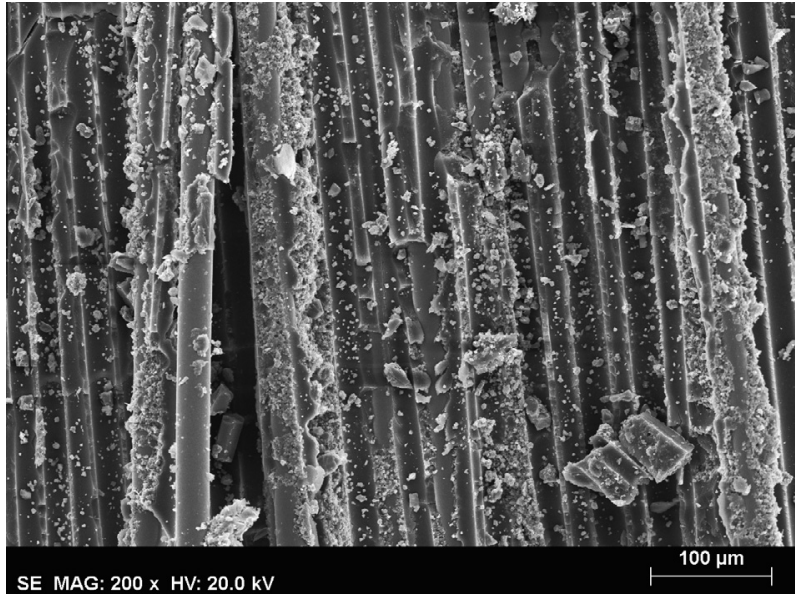

Fig. 11. SEM micrograph of unaged UP pultruded specimen, after bending test (higher magnification).

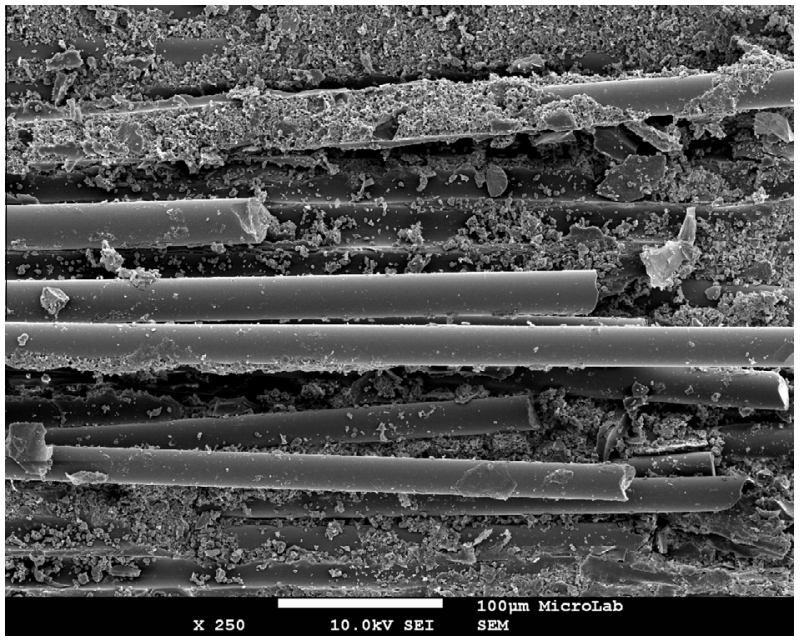

Fig. 12. SEM micrograph of aged UP pultruded specimen, after bending test (higher magnification).

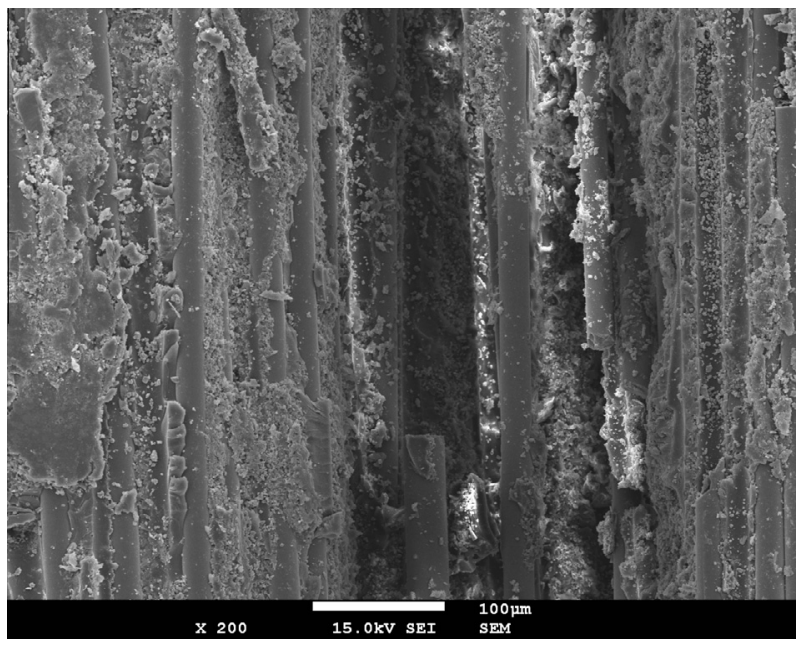

Fig. 13. SEM micrograph of unaged VE pultruded specimen, after bending test.

(compared to tensile properties that are more fibre-dependent), which are believed to be more affected by the thermal cycles. 


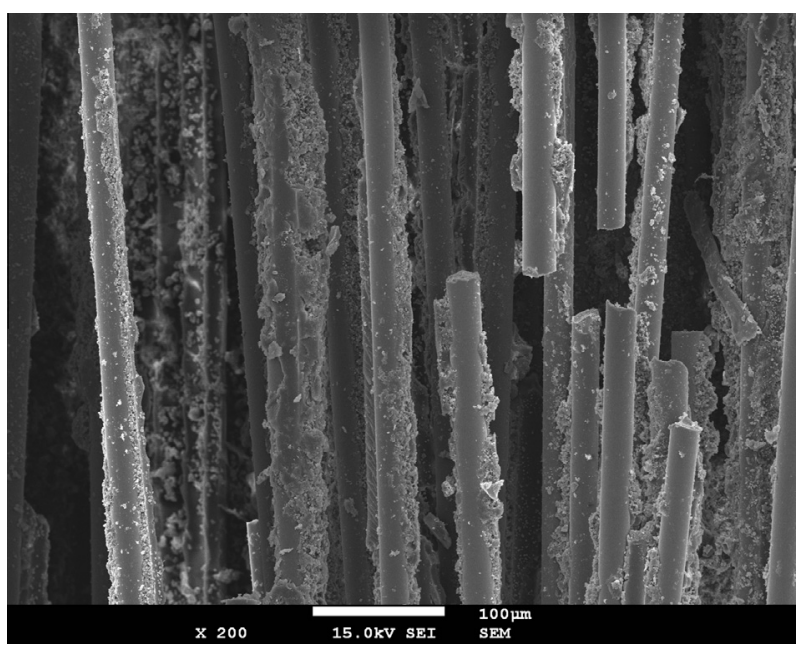

Fig. 14. SEM micrograph of aged VE pultruded specimen, after bending test.

\subsubsection{Interlaminar shear characterisation}

Fig. 8 illustrates the variation of the interlaminar shear strength of both profiles as a function of the number of thermal cycles.

Curves plotted in Fig. 8 show that the interlaminar shear strength of both profiles suffers little variation due to the exposure to thermal cycles. The interlaminar shear strength of both profiles presents a general decreasing trend, with similar (and reduced) levels of degradation and short-beam-shear strength values. For the UP profile, the interlaminar shear strength variation is more consistent, with strength retentions of $91 \%, 94 \%$ and $89 \%$ after 70 , 120 and 190 thermal cycles, respectively. For the VE profile those figures are respectively 95\%, 92\% and $98 \%$.

It is relevant to note that the degradation pattern in the interlaminar shear strength caused by the exposure to thermal cycles illustrated in Fig. 8 is much lower than that caused by the exposure to hygrothermal ageing [2], for which short-beam-strength retention was as low as $50 \%$.

In the study of Kim et al. [22], despite the important differences compared to our experimental work (namely in terms of typology and geometry of the composite system, as well as fibre architecture, and immersion in an alkaline solution), the E-glass vinylester system presented similar behaviour when compared to our VE profile. Regarding the study of Zhang et al. [16], although there were also evident experimental differences, the epoxy system showed similar interlaminar shear strength variation when compared to our polyester profile.

\subsubsection{SEM characterisation}

The SEM characterisation reported here was performed on the fracture surface of either of glass reinforced polyester (UP) or vinylester (VE) pultruded specimens, after mechanical testing. As mentioned, three different testing geometries were considered: tensile, bending and interlaminar shear. For each of type of pultruded material, both aged (190 cycles) and unaged samples were assessed.

Figs. 9 and 10 display low magnification SEM micrographs of bending cracked unaged UP and VE specimens, respectively. Figs. 11 and 12 display high magnification SEM micrographs of, respectively, unaged and aged (190 cycles) UP pultruded specimens, after bending tests. Figs. 13 and 14 display similar SEM micrographs for unaged and aged (190 cycles) VE pultruded specimens, also after bending tests.

For unaged UP pultruded composites (Figs. 9 and 11), both cohesive rupture and adhesive rupture can be observed, the latter appearing to be the (slightly) dominant mechanism. Adhesive rupture occurs at the fibre-matrix interface and, as a result of the fibre-matrix debonding, both the fibre surface and the matrix surface look shiny. Cohesive rupture occurs in the matrix, in the bulk. Crack propagation occurs at the matrix around the fibres, but since the volume fraction of the matrix is relatively small, it is expected that cracks with origin in the matrix may also include the matrix-fibre interface in some part of their way. Consequently, isolated fibres appear coated by the matrix; they do not look fully coated because the tight packing of glass fibres makes it difficult the propagation of cracks to occur exclusively in the matrix. Therefore, fibres isolated by cohesive rupture appear as partially coated by the matrix.

Both cohesive rupture and adhesive rupture can also be observed in unaged VE pultruded composites (Figs. 10 and 13). In this case, cohesive rupture appears to be the dominant mechanism, as a consequence of better adhesion between the VE matrix and the glass fibres. The same patterns are observed for cracked samples after tensile or shear testing.

Fig. 11 (unaged) and Fig. 12 (190 cycles) show that thermal cycles ageing has two main consequences in UP pultruded specimens: (i) some degradation of the fibre-matrix interface, increasing the relative weight percentage of fibre-matrix debonding, and (ii) some degradation of the matrix itself, evidenced by matrix cracking debris of micron size. Crack propagation in a degraded matrix originates secondary cracks (crack multiplication is easier as degradation proceeds).

As compared to polyester resins, poly(vinyl-ester) resins are expected to present better resistance to thermal cycles degradation and this is the case, as illustrated in Fig. 13 (unaged) and Fig. 14 (190 cycles). Less adhesive debonding in both figures is associated to improved resistance of the fibre-matrix interface. On the other hand, no evidence of extensive microcracking was found in the VE matrix: cohesive rupture is not associated to extensive microcracking, as it is observed in UP (cured) resins.

\section{Conclusions}

This paper presented a literature review and an experimental study about the effects of thermal cycles likely to be experienced in Mediterranean mild climates by GFRP pultruded profiles made of unsaturated polyester and vinylester resins. The results obtained allow drawing the following conclusions:

1. In general, both types of GFRP profiles presented low to moderate degradation of their mechanical properties due to thermal cycles, particularly when compared to higro-thermal and hydro-thermal degradation experienced by those same materials [12].

2. DMA analysis indicates no evident structural changes in the resin matrix as well as at the fibre-matrix interphase, showing only slight changes in the glass transition temperature of both profiles. In addition, for the VE profile, results suggest the existence of post-curing effects due to the higher temperature exposure ranges.

3. In terms of tensile properties and interlaminar shear strength, both types of GFRP profiles suffered slight changes. For the UP profile, the tensile and interlaminar shear strengths decreased $13 \%$ and $11 \%$, respectively. For the VE profile, the tensile strength presented an overall increasing trend (opposite to that of the UP profile). After 190 cycles, the tensile strength of the VE profile increased $8 \%$, while the interlaminar shear strength presented a $2 \%$ reduction.

4. Regarding the flexural properties, they were negatively and more considerably affected in both types of GFRP profiles. The flexural strength decreased $11 \%$ and $13 \%$ for the UP and VE 
profiles, respectively, whereas their flexural modulus were reduced by as much as $24 \%$ and $25 \%$, respectively. Such increased magnitude (namely, when compared to tensile properties) is deemed to have been caused by the stronger dependency of flexural properties on the resin matrix and the fibre-matrix interphase. The degradation of flexural properties was more pronounced in the first set of cycles and it tended to stabilize for increasing thermal cycles.

5. SEM observations on crack surfaces provide evidence that two main processes are involved in crack initiation: adhesive rupture (fibre debonding) and cohesive rupture (matrix cracking). VE resins show better fibre-matrix adhesion and improved interphase resistance, as compared to UP resins. Also the VE matrix resisted better to the thermal cycles than the UP matrix: in the former pultruded composite fibre-matrix debonding occurs in less extent, and matrix microcracking is scarcely present.

6. Overall, the VE profile presented better mechanical performance when compared to the UP profile, particularly in what concerns the tensile and interlaminar shear properties. Given the same fibre content and architecture of those profiles, such improved performance stems from the improved durability of the vinylester matrix system together with the abovementioned post-curing phenomenon.

\section{Acknowledgements}

The authors wish to acknowledge the support of ICIST, LNEC, FCT and Agência da Inovação (Grant No. 2014/38967) for funding this research and also to ALTO Perfis Pultrudidos Lda. for supplying the GFRP profiles used in the experimental tests. The first author also wishes to thank FCT for funding his PhD scholarship (Grant No. SFRH/BD/88467/2012). António Correia Diogo acknowledges the assistance of Eng. Isabel Nogueira in the SEM experiments, namely in the preparation of samples and the help in observations.

\section{References}

[1] Bakis CE, Bank LC, Brown VL, Cosenza E, Davalos JF, Lesko JJ, et al. Fibrereinforced polymer composites for construction. State-of-the-art review. Compos or Constr 2002;6:73-87.

[2] Correia JR, Cabral-Fonseca S, Branco FA, Ferreira JG, Eusébio MI, Rodrigues MP. Durability of pultruded glass-fiber-reinforced polyester profiles for structural applications. Mech Compos Mater 2006;42:325-38.

[3] Bai Y, Post NL, Lesko JJ, Keller T. Experimental investigations on temperaturedependent thermo-physical and mechanical properties of pultruded GFRP composites. Thermochim Acta 2008;469:28-35.

[4] Keller T. Recent all-composite and hybrid fibre-reinforced polymer bridges and buildings. Prog Struct Eng Mater 2001;3:132-40.

[5] Keller T. Towards structural forms for composite fibre materials. Struct Eng Int 1999;9:297-300.

[6] Sobrino JA, Pulido MDG. Towards advanced composite material footbridges Struct Eng Int 2002;12:84-6.

[7] Miesseler HJ, Wolff R. Experience with fiber composite materials and monitoring with optical fiber sensors. Advanced composite materials in civil engineering structures. American Society of Civil Engineering; 1991. p. 167-80.

[8] Correia JR, Branco FA, Silva NMF, Camotim D, Silvestre N. First-order, buckling and post-buckling behaviour of GFRP pultruded beams. Part 1: experimental study. Comput Struct 2011;89:2052-64.

[9] Correia JR, Branco FA, Gonilha JA, Silva N, Camotim D. GFRP pultruded flexura members: assessment of existing design methods. Struct Eng Int 2012;20: 362-9.

[10] Sheikh SA, Tam S. Effect of freeze-thaw climatic conditions on long-term durability of FRP strengthening systems. Ministry of Transportation of Ontario HIIFP-037. 2007:1-40.

[11] Karbhari VM, Chin JW, Hunston D, Benmokrane B, Juska T, Morgan R, et al. Durability gap analysis for fiber-reinforced polymer composites in civil infrastructure. J Compos Constr 2003:7:238-47.

[12] Cabral-Fonseca S, Correia JR, Rodrigues MP, Branco FA. Artificial accelerated ageing of GFRP pultruded profiles made of polyester and vinylester resins: characterisation of physical-chemical and mechanical damage. Strain 2012;48:162-73.
[13] Sousa JM, Correia JR, Cabral-Fonseca S. Durability of glass fibre reinforced polymer pultruded profiles: comparison between QUV accelerated exposure and natural weathering in a Mediterranean climate. Exp Tech 2013.

[14] Dutta PK, Hui D. Low-temperature and freeze thaw durability of thick composites. Compos B Eng 1996;27:371-9.

[15] Gomez JP, Casto B. Freeze-thaw durability of composite materials. Virginia Transportation Research Council VTRC 96-R25. 1996. p. 1-13.

[16] Zhang S, Karbhari VM, Reynaud D. NOL-ring based evaluation of freeze and freeze-thaw exposure effects on FRP composite column wrap systems. Compos B Eng 2001;32:589-98.

[17] Karbhari VM, Rivera J. Cold-temperature and simultaneous aqueous environment related degradation of carbon/vinylester composites. Compos B Eng 2001;33:17-24.

[18] Karbhari VM, Rivera J, Zhang J. Low-temperature hygrothermal degradation of ambient cured E-glass/vinylester composites. J Appl Polym Sci 2002;86: 2255-60.

[19] Tann DB, Delpak R. Influences of freeze and thaw cycles and elevated temperatures on the properties of FRP composites. In: ACIC 2004 conference, University of Surrey; 2004. p. 611-8.

[20] Haramis J, Verghese KNE, Lesko JJ, Weyers RE. Characterization of freeze-thaw damage mechanisms in composites for civil infrastructure. In: Advance composite materials in bridges and structures-international conference. 2000. p. 663-70.

[21] Wu H, Fu G, Gibson R, Yan A, Warnemuende K, Anumandla V. Durability of FRP composite bridge deck materials under freeze-thaw and low temperature conditions. J Bridge Eng 2006;11:443-51.

[22] Kim H-Y, Park Y-H, You Y-J, Moon C-K. Short-term durability test for GFRP rods under various environmental conditions. Compos Struct 2008;83:37-47.

[23] Li H, Xian G, Lin Q, Zhang H. Freeze-thaw resistance of unidirectional-fiberreinforced epoxy composites. J Appl Polym Sci 2012;123:3781-8.

[24] Di Ludovico M, Piscitelli F, Prota A, Lavorgna M, Mensitieri G, Manfredi G. Improved mechanical properties of CFRP laminates at elevated temperatures and freeze-thaw cycling. Constr Build Mater 2012;31:273-83.

[25] Aniskevich K, Korkhov V, Faitelsone J, Janson J. Mechanical properties of pultruded glass fiber reinforced plastic after freeze-thaw cycling. J Reinforced Plast Compos 2012;31:1554-63.

[26] ASTM D 6944. Standard practice for resistance of cured coatings to thermal cycling. West Conshohocken, PA2009.

[27] EN 1504-2. Products and systems for the protection and repair of concrete structures. Definitions, requirements, quality control and evaluation of conformity - Part 2: surface protection systems for concrete. Brussels: European Committee for Standardization; 2006.

[28] EN 1504-3. Products and systems for the protection and repair of concrete structures. Definitions, requirements, quality control and evaluation of conformity - Part 3: structural and non-structural repair. Brussels: European Committee for Standardization; 2006.

[29] EN 1504-4. Products and systems for the protection and repair of concrete structures. Definitions, requirements, quality control and evaluation of conformity - Part 4: structural bonding. Brussels: European Committee for Standardization; 2006.

[30] EN 539-2. Clay roofing tiles for discontinuous laying - determination of physical characteristics - Part 2: test for frost resistance. 2007.

[31] ISO 6721. Plastics - determination of dynamic mechanical properties - Part 1: general principles. Part 5: flexural vibration - non-resonance method. Genève: International Organization for Standardization; 1996.

[32] ISO 14125. Fibre-reinforced plastic composites - determination of flexural properties. Genève: International Organization for Standardization; 1998.

[33] ISO 527. Plastics - determination of tensile properties - Part 1: general principles. Part 4: test conditions for isotropic and orthotropic fibre-reinforced plastic composites. Genève: International Organization for Standardization; 1997.

[34] ASTM D 2344. Standard test method for short-beam strength of polymer matrix composite materials and their laminates. West Conshohocken, PA: American Society for testing and materials; 2000

[35] Adams DF, Miller AK. An analysis of the impact behavior of hybrid composite materials. Mater Sci Eng 1975;19:245-60.

[36] Elber W. Failure mechanics in low velocity impact on thin composite plates. NASA Technical Paper 2152. 1983.

[37] Cantwell JW. Impact damage in carbon fibre composites [PhD thesis]. University of London; 1985.

[38] Vedula M, Koezak MJ. Impact resistance of cross-plied polyphenylene sulfide composites. In: Proceedings of fourth Japan-US conference on composite materials. 1988. p. 72-81.

[39] Clark G. Modelling of impact damage in composite laminates. Composites 1989;20:209-14.

[40] Cantwell WJ, Morton J. The impact resistance of composite materials - a review. Composites 1991;22:347-62.

[41] ASTM D 3171. Standard test method for constituent of composite materials. West Conshohocken, PA: American Society for Testing and Materials; 2009.

[42] ISO 1183. Plastics - methods for determining the density of non-cellular plastics. Part 1: immersion method, liquid pycnometer and titration method. Genève: International Organization for Standardization; 2004.

[43] ASTM E 1640. Standard test method for assignment of the glass transition temperature by dynamic mechanical analysis. West Conshohocken, PA: American Society for Testing and Materials; 1999. 